\title{
Durability Environmental Regionalization for Concrete Structures
}

\author{
Daming Luo, ${ }^{1}$ Yan Wang, ${ }^{2}$ and Ditao Niu ${ }^{1}$ \\ ${ }^{1}$ School of Civil Engineering, Xian University of Architecture and Technology, Xi'an 710055, China \\ ${ }^{2}$ Material Science and Engineering Centers for Postdoctoral Studies, Xian University of Architecture and Technology, \\ Xian 710055, China \\ Correspondence should be addressed to Ditao Niu; niuditao@163.com
}

Received 4 October 2013; Accepted 23 November 2013

Academic Editor: Fei Kang

Copyright (C) 2013 Daming Luo et al. This is an open access article distributed under the Creative Commons Attribution License, which permits unrestricted use, distribution, and reproduction in any medium, provided the original work is properly cited.

\begin{abstract}
Environment is the external factor that affects the durability of concrete structures. Buildings in different regions with different climates will respond to durability deterioration in different ways. For macroenvironmental regionalization, the dominant factor analysis method of the climatic zonation was applied into the environmental regionalization in this paper. Based on the environmental characteristics in China and the effect of environmental factor on the durability of concrete structure, the proper regionalization indexes are chosen, and the environmental regionalization is made. For microenvironmental regionalization, fuzzy set and rough set theories were used in date mining on discrete measured data, and the weight determination of various factors affecting durability was transformed into evaluation of the significance of attributes among rough sets. The method of durability environmental regionalization is established by analyzing the degree of influence that various factors have on the durability of concrete structures. The result of durability environmental regionalization for concrete structures in Shenzhen city shows that the proposed approach is reasonable.
\end{abstract}

\section{Introduction}

The concrete structures are located in a changeable environment, different regional environment leads to different damage mechanism and different damage level, and the structural durability degradation form has its regional characteristics. It means a lot to insure the concrete construction durability and to extend the service life if a reasonable durability design method combing with the various environmental conditions can be found.

Durability environmental regionalization is to divide a region into different areas according to the environmental conditions which influence the durability of the concrete structure. The influence of the environment on the architecture is involved in many professional fields, from architectural planning, design, and construction to the building operation and management. The architects have long ago realized the influence of the climate on the architectural design. Early in 1949-1952, the American Institute of Architects (AIA) proposed the principle of the architectural design under the influence of different climates in the main areas of the USA
[1]. The research on the weather in China began in the 1950s, and "Standard of Climatic Regionalization for Architectural" was issued in 1993 [2], but these research achievements was aimed at the influence of climate condition on the function of the building. Jin and Lü [3] had made durability environmental regionalization on Zhejiang Province; however, the regionalization doesnot have uniform indexes; only cursory regionalization according to the influence of the environment on the durability of the concrete structure was proposed.

The durability environmental regionalization for concrete structures is a problem of complex multiparameter and multiindex evaluation, and the selection and determination of the regionalization index directly relate to the accuracy of the regionalization. In the macroenvironmental regionalization, this paper will introduce the combination of dominant factor and comprehensive analysis method of the climatic zonation into durability environmental regionalization and select property indexes according to the environmental characteristics in each area of China, while in the microenvironmental regionalization, instead of macroscopic regionalization 
methods, a new way, which is based on the fuzzy sets and rough sets to determine the weight distribution, is proposed in this paper to make a quantitative calculation for durability regionalization indexes and improve the regionalization quality and precision. This method allowed the durability environment regionalization to be done in specific city or area, which can reflect the durability influencing factors in the microenvironment around the buildings.

\section{Macroenvironmental Regionalization}

2.1. Regionalization Method. According to the climate condition and erosion medium characteristics in China, the environment around engineering structure can be divided into atmospheric environment, water environment, and soil environment. Moreover, the atmospheric environment can be divided into general atmospheric environment (including rural area and urban area), marine atmospheric environment, and industrial atmospheric environment; the water environment can be divided into seawater environment, freshwater environment, and industrial water environment, and the soil environment can be divided into alkaline soil, acid soil, inland saline soil, and coastal saline soil.

The principle of climate regionalization generally includes principle of dominant factor, principle of comprehensive analysis and combination of the both. The dominant factor principle advocates using uniform indexes, while the principle of comprehensive analysis laid stress on the climate similarity among regions instead of uniform indexes. In the durability environmental regionalization, factors influencing concrete durability such as the atmospheric temperature and humidity, the distance from coastline, and the acid rain situation. should be considered. Therefore, it would be necessary to employ the combination of dominant factor and comprehensive analysis method of the climatic zonation to make the durability environmental regionalization. Due to the various distribution of spatial and temporal of the environment elements and the different influence of each environmental element on the durability environmental regionalization, this paper will use two-level regionalization approach to make durability environmental regionalization for concrete structures.

2.2. Regionalization Index. The environmental factors that affect concrete durability include (1) climate condition, such as atmospheric temperature, relative humidity, and precipitation, which are closely related to freeze-thaw damage, concrete carbonization, reinforcing steel corrosion, and chloride ion penetration; (2) Erosion medium, such as carbon dioxide, chloride, acid rain, and sulfate. The selection of environmental index is the key issue of durability environmental regionalization. Here we will choose the regionalization index for each grade of regionalization, respectively.

(1) Primary Regionalization Index. The primary regionalization is made mainly according to the environmental factor that affects the durability in the overall country. The atmospheric $\mathrm{CO}_{2}$ concentration has little contrasts, and the atmospheric $\mathrm{Cl}^{-}$content shows large gradient only in the coastal area. Therefore, the density of $\mathrm{CO}_{2}$ and the $\mathrm{Cl}^{-}$ content will not be used as the main index. The distribution of environmental temperature and relative humidity, which reflects the main difference of climate characteristic, has large difference throughout the country and has significant influence on the concrete carbonization, reinforcing steel corrosion and freeze-thaw damage of concrete [4-9]. Therefore, the temperature and relative humidity are selected as the primary regionalization index.

The annual average temperature can comprehensively reflect the influence of the temperature on the durability of concrete structures; the average temperature in January reflects the coldest degree of the area and determines whether frost freeze-thaw cycle damage occurs in concrete. Therefore, the annual average temperature and average temperature in January are chosen as the primary index.

July has the highest relative humidity and temperature in the overall year in China, therefore leading to the fastest reinforcing steel corrosion. Hence, the average relative humidity in July is chosen as the humidity index.

(2) Secondary Regionalization Index. The secondary regionalization index was chosen according to the environmental characteristic of each primary area. For coastal environment, the distance from the costal line can well reflect the change of atmospheric $\mathrm{Cl}^{-}$content. Besides, due to the different industrialization in each city, the emission of acid gases such as $\mathrm{SO}_{2}, \mathrm{CO}_{2}, \mathrm{NO}_{2}$, and $\mathrm{H}_{2} \mathrm{~S}$ is different, which leads to different $\mathrm{pH}$ levels of acid rain. Therefore, the distance from the costal line or the annual average $\mathrm{pH}$ of acid precipitation is chosen as the secondary regionalization index, depending on the area location.

2.3. Regionalization Standard. The primary regionalization indexes include annual average temperature $(T)$, January average temperature $\left(T_{1}\right)$, and July average relative humidity $\left(\mathrm{RH}_{7}\right) \cdot T_{1}$ is related to whether frost freeze-thaw cycle damage occurs in the concrete. If $T_{1}$ is lower than $-10^{\circ} \mathrm{C}$, freeze-thaw damage is serious; if it is around $0^{\circ} \mathrm{C}$, freeze-thaw damage may be occur; if $T_{1}$ is higher than $10^{\circ} \mathrm{C}$, frost and freezethaw will not occur in the concrete structure [9]. Therefore, $T_{1}$ is divided into four parts: $T_{1} \leq-10^{\circ} \mathrm{C},\left[-10^{\circ} \mathrm{C} \sim 0^{\circ} \mathrm{C}\right]$, $\left[0^{\circ} \mathrm{C} \sim 10^{\circ} \mathrm{C}\right]$, and $>10^{\circ} \mathrm{C}$. Relative humidity has large effect on concrete carbonation and reinforcing steel corrosion process. The carbonation will have a highest speed when relative humidity is $50 \%$. Besides, the relative humidity is a decisive factor for the degree of pore saturation which, in turn, will influence the transportation of oxygen and chloride ion [10, 11 ], so $50 \%$ is chosen as critical relative humidity.

The secondary regionalization indexes include the distance from coastline $(S)$ and the annual average $\mathrm{pH}$ of acid precipitation $\left(\mathrm{pH}_{w}\right)$. Researches show that if $S$ is more than $3 \mathrm{~km}$, chlorine-ion erosion could be ignored [12], so the critical $S$ can be selected as $3 \mathrm{~km}$. Since rain that has equilibrated with atmospheric $\mathrm{CO}_{2}$ has a $\mathrm{pH}_{w}$ value of about 5.6 and if $\mathrm{pH}_{w}$ value is less than 4.5 , acid rain becomes a serious regional environmental problem [13]. Therefore, 5.6 
TABLE 1: Regionalization standard.

\begin{tabular}{lccc}
\hline & & Primary regionalization criteria & Secondary regionalization criteria \\
\hline I & Ia & $T_{1} \leq-10^{\circ} \mathrm{C} ; T:-4.8 \sim 8^{\circ} \mathrm{C} ; \mathrm{RH}_{7} \geq 50 \%$ & $\mathrm{pH}_{w}>5.6$ \\
& Ib & & $4.5<\mathrm{pH}_{w} \leq 5.6$ \\
\hline & IIa & $T_{1}:-10 \sim 0^{\circ} \mathrm{C} ; T: 8 \sim 14^{\circ} \mathrm{C} ; \mathrm{RH}_{7} \geq 50 \%$ & $\mathrm{pH}_{w}>5.6$ and $S>3 \mathrm{~km}$ \\
II & IIb & & $4.5<\mathrm{pH}_{w} \leq 5.6$ and $S>3 \mathrm{~km}$ \\
& IIc & & $4.5<\mathrm{pH}_{w} \leq 5.6$ and $S \leq 3 \mathrm{~km}$ \\
\hline & III & $T_{1}: 0 \sim 10^{\circ} \mathrm{C} ; T: 14 \sim 20^{\circ} \mathrm{C} ; \mathrm{RH}_{7} \geq 50 \%$ & $4.5<\mathrm{pH}_{w} \leq 5.6$ and $S>3 \mathrm{~km}$ \\
III & III & & $\mathrm{pH}_{w} \leq 4.5$ and $S>3 \mathrm{~km}$ \\
& IIIc & & $\mathrm{pH}_{w} \leq 4.5$ and $S \leq 3 \mathrm{~km}$ \\
\hline & IVa & $T_{1}>10^{\circ} \mathrm{C} ; T: 20 \sim 25^{\circ} \mathrm{C} ; \mathrm{RH}_{7} \approx 80 \%$ & $4.5<\mathrm{pH}_{w} \leq 5.6$ and $S \geq 3 \mathrm{~km}$ \\
IV & IVb & & $\mathrm{pH}_{w} \leq 4.5$ and $S \geq 3 \mathrm{~km}$ \\
& IVc & V & $4.5<\mathrm{pH}_{w} \leq 5.6$ and $S \leq 3 \mathrm{~km}$ \\
\hline V & VI & $T_{1} \leq-10^{\circ} \mathrm{C} ; T: 2 \sim 9^{\circ} \mathrm{C} ; \mathrm{RH}_{7} \leq 50 \%$ & $\mathrm{pH}_{w}>5.6$ \\
\hline VI & & $T_{1}:-10 \sim 0^{\circ} \mathrm{C} ; T: 10 \sim 14^{\circ} \mathrm{C} ; \mathrm{RH}_{7} \leq 50 \%$ & $\mathrm{pH}_{w}>5.6$ \\
\hline
\end{tabular}

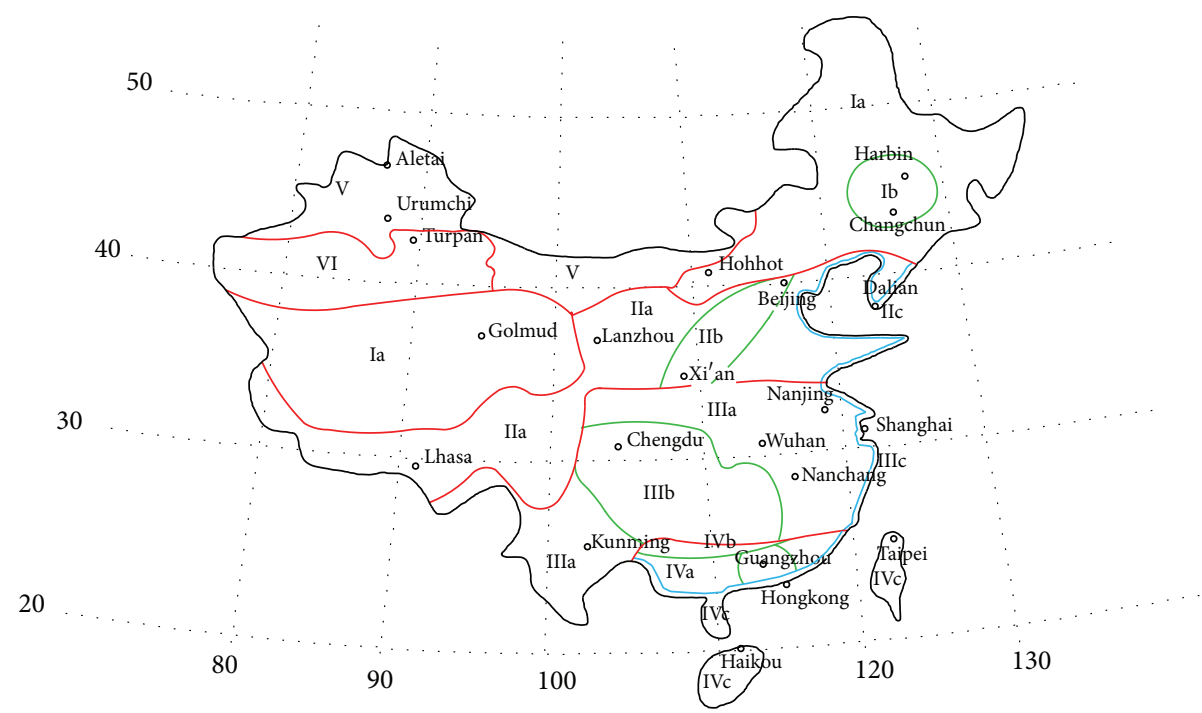

FIGURE 1: Regionalization map of durability environment for concrete structures in China.

and 4.5 are chosen as critical $\mathrm{pH}_{w}$ of acid rain. Detailed regionalization standard is shown in Table 1.

2.4. Regionalization Result. According to the primary and secondary regionalization criteria of durability environmental regionalization standard, China can be divided into six primary regions and thirteen secondary regions. The result is shown in Figure 1, and the environmental character and main reason of durability degradation of every regions are provided in Table 2.

\section{Microenvironmental Regionalization}

For Macroenvironmental regionalization, the method mentioned above can give a qualitative division for a large-scale environment. For microenvironmental regionalization of a small-scale environment, the following method will give a precise division based on quantitative indicators.

\subsection{Fuzzy Cluster Analysis and the Rough Set}

3.1.1. Fuzzy Cluster Analysis. Traditional cluster analysis is a hard regionalization method, which divided each object into a certain category, and it cannot satisfy the field requirement. With the intermediary in their properties, the type of objective things is often not very clear. However, fuzzy cluster analysis can effectively deal with these problems [14-16], Fuzzy clustering methods allow objects to belong to several clusters simultaneously with different degrees of membership. In many field situations, fuzzy clustering is more natural than hard clustering, as objects on the boundaries between several classes are not forced to fully belong to one of the classes.

For durability environmental regionalization, let $\mathbf{X}=$ $\left\{x_{1}, x_{2}, \ldots, x_{n}\right\}$ be all buildings to be tested; these buildings will be divided into different categories according to their durability degradation causes; each sample $\mathbf{x}_{i}=$ $\left\{x_{i 1}, x_{i 2}, \ldots, x_{i m}\right\}$ consists of $m$ measured testing value of the 
TABLE 2: Environmental character and main reason of durability degradation of every regions.

\begin{tabular}{|c|c|c|c|c|}
\hline \multicolumn{2}{|c|}{ Regions } & \multirow{3}{*}{$\begin{array}{l}\text { Environmental character of primary regions } \\
\text { This region has a long frigid winter which } \\
\text { lasts } 6 \text { months or more; the January average } \\
\text { temperature is }-31 \sim-10^{\circ} \mathrm{C} \text {; and the number } \\
\text { of annual snowfall days is } 5 \sim 100 \text { days with a } \\
\text { long freezing period. }\end{array}$} & \multirow{2}{*}{$\begin{array}{c}\text { Environmental character } \\
\text { of secondary regions } \\
\begin{array}{c}\text { No acid rain, far from } \\
\text { coastline }\end{array}\end{array}$} & \multirow{2}{*}{$\begin{array}{c}\text { Main reason of durability degradation } \\
\text { Serious freeze-thaw damage, concrete } \\
\text { carbonation, and reinforcing steel } \\
\text { corrosion }\end{array}$} \\
\hline & Ia & & & \\
\hline 1 & $\mathrm{Ib}$ & & $\begin{array}{l}4.5<\mathrm{pH}_{w} \leq 5.6, \text { far } \\
\quad \text { from coastline }\end{array}$ & $\begin{array}{l}\text { Serious freeze-thaw damage, slightly acid } \\
\text { rain corrosion, concrete carbonation, } \\
\text { and reinforcing steel corrosion }\end{array}$ \\
\hline \multirow{3}{*}{ II } & IIa & \multirow{3}{*}{$\begin{array}{l}\text { This region has a long dry-cold winter; the } \\
\text { January average temperature and minimum } \\
\text { temperature in January are }-10 \sim 0^{\circ} \mathrm{C} \text { and } \\
-20 \sim-30^{\circ} \mathrm{C} \text {, respectively; the number of } \\
\text { annual snowfall days is usually less than } 50 \\
\text { days. }\end{array}$} & $\begin{array}{l}\text { No acid rain, far from } \\
\text { coastline }\end{array}$ & $\begin{array}{c}\text { Freeze-thaw damage, concrete } \\
\text { carbonation, reinforcing steel corrosion }\end{array}$ \\
\hline & IIb & & $\begin{array}{l}4.5<\mathrm{pH}_{w} \leq 5.6, \text { far } \\
\text { from coastline }\end{array}$ & $\begin{array}{l}\text { Freeze-thaw damage, concrete } \\
\text { carbonation, and reinforcing steel } \\
\text { corrosion, slightly acid rain corrosion }\end{array}$ \\
\hline & IIc & & $\begin{aligned} 4.5< & \mathrm{pH}_{w} \leq 5.6, \text { closer } \\
& \text { to the coast }\end{aligned}$ & $\begin{array}{l}\text { Chloride ion corrosion, freeze-thaw } \\
\text { damage, concrete carbonation, } \\
\text { reinforcing steel corrosion, slightly acid } \\
\text { rain corrosion }\end{array}$ \\
\hline \multirow{3}{*}{ III } & IIIa & \multirow{3}{*}{$\begin{array}{l}\text { Most of the parts of this region have a cold } \\
\text { and clammy winter; the January average } \\
\text { temperature is } 0 \sim 10^{\circ} \mathrm{C} \text {; the minimum } \\
\text { temperature can drop below }-10^{\circ} \mathrm{C} \text {; the } \\
\text { number of annual rainy days and snowfall } \\
\text { days is about } 150 \text { days and } 0 \sim 15 \text { days, } \\
\text { respectively. }\end{array}$} & $\begin{array}{l}4.5<\mathrm{pH}_{w} \leq 5.6, \text { far } \\
\quad \text { from coastline }\end{array}$ & $\begin{array}{l}\text { Slightly acid rain corrosion, concrete } \\
\text { carbonation, reinforcing steel corrosion, } \\
\text { and slightly freeze-thaw damage }\end{array}$ \\
\hline & IIIb & & $\begin{aligned} \mathrm{pH}_{w} & \leq 4.5, \text { far from } \\
& \text { coastline }\end{aligned}$ & $\begin{array}{l}\text { Severe acid rain, concrete carbonation, } \\
\text { reinforcing steel corrosion, and slightly } \\
\text { freeze-thaw damage }\end{array}$ \\
\hline & IIIC & & $\begin{array}{c}\mathrm{pH}_{w} \leq 4.5, \text { closer to the } \\
\text { coast }\end{array}$ & $\begin{array}{c}\text { Chloride ion corrosion, severe acid rain, } \\
\text { concrete carbonation, reinforcing steel } \\
\text { corrosion }\end{array}$ \\
\hline \multirow{3}{*}{ IV } & IVa & \multirow{3}{*}{$\begin{array}{l}\text { This region has a long summer and no } \\
\text { winter; the January average temperature is } \\
\text { higher than } 10^{\circ} \mathrm{C} \text {, and average annual } \\
\text { temperature is higher than } 20^{\circ} \mathrm{C} \text {; there is no } \\
\text { significant difference among the four } \\
\text { seasons, the average annual rainfall day is } \\
\text { about } 120 \sim 200 \text { days. }\end{array}$} & $\begin{array}{l}4.5<\mathrm{pH}_{w} \leq 5.6, \text { far } \\
\quad \text { from coastline }\end{array}$ & $\begin{array}{c}\text { Concrete carbonation, slightly acid rain } \\
\text { corrosion, and reinforcing steel } \\
\text { corrosion }\end{array}$ \\
\hline & $\mathrm{IVb}$ & & $\begin{aligned} \mathrm{pH}_{w} & \leq 4.5, \text { far from } \\
\text { coastline } & \end{aligned}$ & $\begin{array}{l}\text { Severe acid rain, concrete carbonation, } \\
\text { and reinforcing steel corrosion }\end{array}$ \\
\hline & IVc & & $\begin{aligned} 4.5< & \mathrm{pH}_{w} \leq 5.6, \text { closer } \\
& \text { to the coast }\end{aligned}$ & $\begin{array}{l}\text { Chloride ion corrosion, concrete } \\
\text { carbonation, slightly acid rain corrosion, } \\
\text { and reinforcing steel corrosion }\end{array}$ \\
\hline $\mathrm{V}$ & $\mathrm{V}$ & $\begin{array}{l}\text { This region has a cold winter and hot dry } \\
\text { summer; the January average temperature is } \\
-10 \sim-22^{\circ} \mathrm{C} \text {, and minimum temperature is } \\
\text { lower than }-40^{\circ} \mathrm{C} \text {; the July average relative } \\
\text { humidity is lower than } 50 \% \text {; the annual } \\
\text { snowfall days is } 5 \sim 100 \text { days. }\end{array}$ & $\begin{array}{l}\text { No acid rain, far from } \\
\text { coastline }\end{array}$ & $\begin{array}{l}\text { Serious freeze-thaw damage, concrete } \\
\text { carbonation, }\end{array}$ \\
\hline VI & VI & $\begin{array}{l}\text { This region has a dry-cold winter and hot } \\
\text { summer; the January average temperature is } \\
0 \sim-10^{\circ} \mathrm{C} \text {; the July average relative humidity } \\
\text { is lower than } 50 \% \text {; the annual snowfall days } \\
\text { is } 5 \sim 20 \text { days. }\end{array}$ & $\begin{array}{l}\text { No acid rain, far from } \\
\text { coastline }\end{array}$ & $\begin{array}{l}\text { Freeze-thaw damage and concrete } \\
\text { carbonation }\end{array}$ \\
\hline
\end{tabular}

durability factor. Then, we can obtain the raw $n \times m$ data matrix.

Fuzzy clustering analysis as follows [16].

Step 1 (data standardization). In order to compare different testing values with different dimensions, the measured data should be standardized. A collection of numeric data is standardized by subtracting a measure of central location (such as the mean or median) and dividing it by some measure of spread (such as the standard deviation or range). The commonly methods of standardization are Translation.Standard
Deviation Transformation and Translation-Range Transformation,

$$
\begin{gathered}
x_{i j}^{\prime}=\frac{x_{i j}-\mu_{j}}{s_{j}}, \\
x_{i j}^{\prime}=\frac{x_{i j}-\min \left\{x_{i j}\right\}}{\max _{1 \leq i \leq n}\left\{x_{i j}\right\}-\min _{1 \leq i \leq n}\left\{x_{i j}\right\}},
\end{gathered}
$$

where $\mu_{j}$ and $s_{j}$ are the mean value and standard deviation of $x_{i j}$, respectively; and $i=1,2, \ldots, n, j=1,2, \ldots, m$. 
Step 2. Establish the fuzzy similar matrix $\mathbf{R}$. The correlation coefficient $r_{i j}=\mathbf{R}\left(x_{i}, x_{j}\right)$ between $x_{i}$ and $x_{j}$ can be calculated using standardized data and build the fuzzy similar matrix.

Step 3. Establish the fuzzy equivalent matrix $\mathbf{R}^{*}$. Fuzzy similar matrix $\mathbf{R}$ is a fuzzy matrix and may not be transferable. In order to cluster these objects, the square method can be used in finding the equivalent matrix $\mathbf{R}^{*}$. Stepwise compute $\mathbf{R}^{2}, \mathbf{R}^{4}, \ldots$, until $\mathbf{R}^{k}=\mathbf{R}^{2 k}=\mathbf{R}^{2}$.

Step 4. Cluster analysis. According to different confidence level $\lambda \in[0,1]$, the ranks of the fuzzy equivalent matrix $\mathbf{R}^{*}$ obtained in Step 3 can be gradually merged into different clustering results. when $r_{i j} \geq \lambda$, the correlation between the samples is strong enough, and the samples can be classified as the same class. For durability environmental regionalization, factors influencing durability of concrete can be treated as similar. The greater the value of $\lambda$ is, the higher the stability of sample element is, and more details can be distinguished. However, the smaller the value of $\lambda$ is, the less accurate the classification results is. Therefore, the variance of $\lambda$ causes different classification results and forms a dynamic cluster result. In order to determine the optimal threshold $\lambda, \mathbf{F}$ statistics method is used in this paper. In the process of cluster analysis, first obtain the center vector through raw data matrix:

$$
\begin{aligned}
\overline{\mathbf{x}} & =\left(\bar{x}_{1}, \bar{x}_{2}, \ldots, \bar{x}_{k}, \ldots, \bar{x}_{m}\right), \\
\bar{x}_{k} & =\frac{1}{n} \sum_{i=1}^{n} x_{i k}, \quad k=1,2, \ldots m,
\end{aligned}
$$

where $\overline{\mathbf{x}}$ is the center vector of the sample space.

Assume that there are $r$ kinds of classes for certain $\lambda$, and samples size of the $j$ th class is $n_{j}$. The samples in the $j$ th class are recorded as $x_{1}^{(j)}, x_{2}^{(j)}, \ldots, x_{n_{j}}^{(j)}$ and the center vector of the $j$ th class is $\overline{\mathbf{x}}^{(j)}=\left(\bar{x}_{1}^{(j)}, \bar{x}_{2}^{(j)}, \ldots, \bar{x}_{k}^{(j)}, \ldots, \bar{x}_{m}^{(j)}\right)$, where $\bar{x}^{(j)}$ is the mean value of $k$ th feature. Consider

$$
\bar{x}_{k}^{(j)}=\frac{1}{n_{j}} \sum_{i=1}^{n_{j}} x_{i j}^{(j)}, \quad k=1,2, \ldots, m .
$$

The random variable

$$
F=\frac{\sum_{j=1}^{r} n_{j}\left\|\overline{\mathbf{x}}^{(j)}-\overline{\mathbf{x}}\right\|^{2} /(r-1)}{\sum_{j=1}^{r} \sum_{i=1}^{n_{j}}\left\|\mathbf{x}_{i}^{(j)}-\overline{\mathbf{x}}^{(j)}\right\|^{2} /(n-r)}
$$

is a F-distribution with $(n-1, n-r)$ degrees of freedom. Here $\left\|\overline{\mathbf{x}}^{(j)}-\overline{\mathbf{x}}\right\|=\sqrt{\sum_{k=1}^{m}\left(\bar{x}_{k}^{(j)}-\bar{x}_{k}\right)^{2}}$ is the distance between $\overline{\mathbf{x}}^{(j)}$ and $\overline{\mathbf{x}}$, and $\left\|\mathbf{x}_{i}^{(j)}-\overline{\mathbf{x}}^{(j)}\right\|$ is the distance between sample $\mathbf{x}_{i}^{(j)}$ and center vector $\overline{\mathbf{x}}_{i}^{(j)}$ in $j$ th class. Numerator of $\mathbf{F}$ distribution suggests the distances between different classes, and denominator of F-distribution suggests the distances between samples in the same class. Hence the larger $\mathbf{F}$, the longer the distances between different classes, and the better the cluster result.
3.1.2. The Theory of the Rough Set. The theory of rough set, which is proposed by the mathematician Pawlak some 30 years ago, is a new approach to decision making in the presence of uncertainty and vagueness. The main idea of this theory is to make determination or regionalization by knowledge reduction on the basis of maintain resolving ability. Due to the feature that it does not make any presumptions or require a priori knowledge about the data, rough set has been widely used in the fields of data mining, pattern recognition, machine learning, and intelligent control successfully [17-21].

With the development of testing methods [22, 23], we can easily get the durability environmental data of concrete structures; however, due to the randomness of the practical project, statistical analysis for the factors affecting structural durability cannot be proposed. To solve this problem, the rough set theory is introduced to obtain the significance of various environmental factors affecting the durability of concrete structures.

Definition 1. Knowledge representation system is as follows:

$$
S=(U, A, V, f)
$$

where $U$ is the sample set; $A=C \cup D$ is the attribute set, in which $C$ and $D$ are the condition attributes and the decision attributes of the samples, respectively; $V=\cup_{a \in A} V_{a}$ is the set of attribute values; and $f: U \times(C \cup D) \rightarrow V$ is an information functions which specifies the property value for each sample of $U$. Each subset of attributes $R \subseteq A$ determines an indistinguishable binary relation $\operatorname{IND}(R)$ :

$$
\operatorname{IND}(R)=\{(x, y) \in U \times U \mid \forall a \in R, f(x, a)=f(y, a)\} .
$$

Definition 2. Given knowledge representation system $S=$ $(U, A, V, f)$, for each subset $X \subset U$ and an indistinguishable relation $R \subset A$, the upper approximation set and lower approximation set of $X$ can be defined as follows:

$$
\begin{gathered}
R^{-}(X)=\bigcup\left\{Y \subset \frac{U}{\operatorname{IND}(R)} \mid Y \bigcap X \neq \emptyset\right\}, \\
R_{-}(X)=\bigcup\left\{Y \subset \frac{U}{\operatorname{IND}(R)} \mid Y \subset X\right\} .
\end{gathered}
$$

Definition 3. The dependence between the two attribute sets $C$ and $D$ can be defined as follows:

$$
\gamma(C, D)=\frac{\left|\operatorname{POS}_{C}(D)\right|}{|U|},
$$

where $\operatorname{POS}_{C}(D)=C_{-}(D)$, and $|U|$ is the number of the set element.

Definition 4. Attribute $a \in C$, the significance to $D$ of attribute $a$ can be defined as follows:

$$
\operatorname{SGF}(a, C, D)=\gamma(C, D)-\gamma(C-\{a\}, D),
$$


where $\gamma(C-\{a\}, D)$ is the dependence degree of the condition attribute on the decision attribute when remove attribute $a$ from $C$.

\subsection{Method of Index Weight Allocation for the Durability} Environmental Regionalization. When doing regionalization, the weight of indexes should be allocated due to the durability of concrete structures affected by various factors. Using rough set theory to determine the weight of the various regionalization indexes is that using attributes reduction of the rough set to determine the significance of each index under the premise of maintaining the ability of classification. Specific steps are as follows.

Step 1. Taking all samples tested as objects set $C=$ $\left\{c_{1}, c_{2}, \ldots, c_{n}\right\}$, the durability environmental regionalization index $\left(c_{i 1}, c_{i 2}, \ldots, c_{i m}\right)$ as condition attributes, the component durability damage level $\left(d_{1}, d_{2}, \ldots, d_{m}\right)$ as decision attributes, we can obtain the raw data matrix as follows:

$$
A=\left[\begin{array}{ccccc}
c_{11} & c_{12} & \cdots & c_{1 m} & d_{1} \\
c_{21} & c_{22} & \cdots & c_{2 m} & d_{2} \\
\vdots & \vdots & \ddots & \vdots & \vdots \\
c_{n 1} & c_{n 2} & \cdots & c_{n m} & d_{m}
\end{array}\right],
$$

and then, make classification according to the traditional fuzzy clustering analysis.

Step 2. Determine the threshold value $\lambda$ of the best confidence level by $\mathbf{F}$-statistic, then make equivalence partitioning of the detected buildings according to the durability environmental regionalization index and the durability damage level, and then obtain the best classification,

$$
Y=\left\{Y_{1}, Y_{2}, \ldots, Y_{s}\right\}
$$

where $Y_{i}$ represents a compressible set, which can be regard as a set of equivalence relations that corresponds to a durability damage level.

Step 3. In order to find out the significance of index $c_{i}(i=$ $1,2, \ldots, m)$, we can first remove the index and then take fuzzy cluster analysis to the data matrix using the Step 2 method; then we can get the category set after removing the index $c_{i}$ in turn:

$$
E=\left\{E_{1}, E_{2}, \ldots, E_{m}\right\}
$$

where $E_{i}=\left\{Y_{1}^{(i)}, Y_{2}^{(i)}, \ldots, Y_{k}^{(i)}\right\}$ is the classification equivalence set after removing the $i$ th regionalization index, and for different $i, k$ is different. And $Y_{l}^{(i)}(1 \leq l \leq k)$ is the $i$ th classification equivalence set.

Step 4. Using rough set theory to solve the significance of each index. First solve the union lower of approximate set of each equivalence set of each durability damage level respectively. Cobsider

$$
\operatorname{POS}_{C-\left\{c_{i}\right\}}(D)=\left\{C-\left\{c_{i}\right\}\right\}_{-}(D)=\bigcup\left\{\left\{C-\left\{c_{i}\right\}\right\}_{-} Y_{l}\right\} .
$$

For each regionalization index $c_{i}$, the dependence degree of durability damage level $D$ on the regionalization index set $C$ and the regionalization index set $C-c_{i}$ were solved, respectively, by Definition 3 of rough set. Consider

$$
\begin{gathered}
\gamma(C, D)=\frac{\left|\operatorname{POS}_{C}(D)\right|}{|U|}, \\
\gamma\left(C-\left\{c_{i}\right\}, D\right)=\frac{\left|\operatorname{POS}_{C-\left\{c_{i}\right\}}(D)\right|}{|U|} .
\end{gathered}
$$

Then solve the significance SGF $\left(c_{i}, C, D\right)$ of the regionalization index set $c_{i}$ according to Definition 4 of rough set.

Step 5. According to the significance of each regionalization index, allocate weight using the normalization method and get more intuitive results:

$$
W_{i}=\frac{\operatorname{SGF}\left(c_{i}, C, D\right)}{\sum_{k=1}^{m} \operatorname{SGF}\left(c_{k}, C, D\right)} .
$$

The knowledge system was established through the establishment of relational data model and the characterization of attribute value; then calculate the factor weight through the support degree and significance analysis of evaluation object under the data driven. This is an objective allocation method of the index weights of durability regionalization proposed in this paper.

\subsection{Durability Environmental Regionalization for Concrete} Structures in Shenzhen City. The influence factors detection and damage level assessment of durability was taken for 515 in-service concrete structures in Shenzhen city. Considering the operability of field detection, the concrete carbonation depth, chloride ion content of the concrete surface, ambient temperature, and relative humidity are taken as the index of durability environmental regionalization. In order to express the weights allocation process, the detect results of the outdoor trestle of Yantian fishing port, the teaching building of ShenZhen Donghe primary school, and the Bio entertainment center of sea world are taken for examples. Select 20 detected samples as the sample space $U=\{1,2, \ldots, 20\}$, and the condition attribute set $C=\left\{c_{1}, c_{2}, c_{3}, c_{4}\right\}$ are four durability environmental regionalization indexes, which are the concrete carbonation depth, surface chloride concentration, ambient temperature, and ambient relative humidity, respectively. The decision attribute set $D=\{d\}$ is the durability damage level of the concrete components, which can be calculated according to "standard for durability assessment of concrete structures CECS 220:2007" [24]. Where (1) represents that components almost have no durability damage; (2) represents that components have mechanical damage or slight durability damage; (3) represents that components have some relatively serious durability damage; and (4) represents that components have serious durability damage. The detecting data are show in Table 3.

In order to eliminate the impact of dimension, the standard derivation method is used to obtain standardized sample matrix $\mathbf{R}$; and the Euclidean distance method is 
TABLE 3: Detecting data of concrete structures (extract).

\begin{tabular}{|c|c|c|c|c|c|}
\hline \multirow[b]{2}{*}{ Sample number } & \multicolumn{5}{|c|}{ Durability environmental regionalization index } \\
\hline & $\begin{array}{c}\text { Concrete } \\
\text { carbonation } \\
\text { depth }(\mathrm{mm})\end{array}$ & $\begin{array}{l}\text { Surface chloride } \\
\text { concentration }(\%)\end{array}$ & $\begin{array}{c}\text { Ambient temperature } \\
\left({ }^{\circ} \mathrm{C}\right)\end{array}$ & $\begin{array}{l}\text { Ambient relative } \\
\text { humidity }(\%)\end{array}$ & $\begin{array}{c}\text { Durability } \\
\text { damage level }\end{array}$ \\
\hline 1 & 17 & 1.39 & 23.91 & 80 & 3 \\
\hline 2 & 27 & 0.80 & 23.25 & 72 & 1 \\
\hline 3 & 18 & 2.18 & 23.5 & 79 & 3 \\
\hline 4 & 16 & 1.59 & 23.94 & 83 & 4 \\
\hline 5 & 9 & 1.98 & 23.31 & 85 & 4 \\
\hline 6 & 22 & 0.80 & 23.25 & 75 & 2 \\
\hline 7 & 20 & 2.18 & 23.67 & 80 & 3 \\
\hline 8 & 28 & 0.01 & 22.46 & 74 & 2 \\
\hline 9 & 26 & 0.20 & 22.59 & 72 & 1 \\
\hline 10 & 17 & 2.78 & 23.28 & 79 & 3 \\
\hline 11 & 25 & 0.39 & 22.32 & 74 & 2 \\
\hline 12 & 7 & 2.18 & 23.17 & 86 & 4 \\
\hline 13 & 12 & 2.97 & 23.88 & 84 & 4 \\
\hline 14 & 16 & 1.19 & 22.66 & 84 & 4 \\
\hline 15 & 21 & 0.60 & 23.12 & 78 & 3 \\
\hline 16 & 26 & 0.99 & 22.47 & 73 & 2 \\
\hline 17 & 21 & 2.58 & 22.9 & 80 & 3 \\
\hline 18 & 10 & 2.18 & 23.55 & 85 & 4 \\
\hline 19 & 22 & 0.99 & 22.41 & 80 & 3 \\
\hline 20 & 10 & 2.38 & 22.74 & 86 & 4 \\
\hline $\bar{x}_{k}$ & 18.50 & 1.52 & 23.12 & 79.45 & 2.95 \\
\hline $\bar{s}_{k}$ & 6.26 & 0.88 & 0.51 & 4.76 & 0.97 \\
\hline
\end{tabular}

used to establish fuzzy similar matrix $\mathbf{R}$. Through the square method, we get the transitive closure of $\mathbf{R}$ and then obtain fuzzy equivalent matrix $\mathbf{R}^{*}$

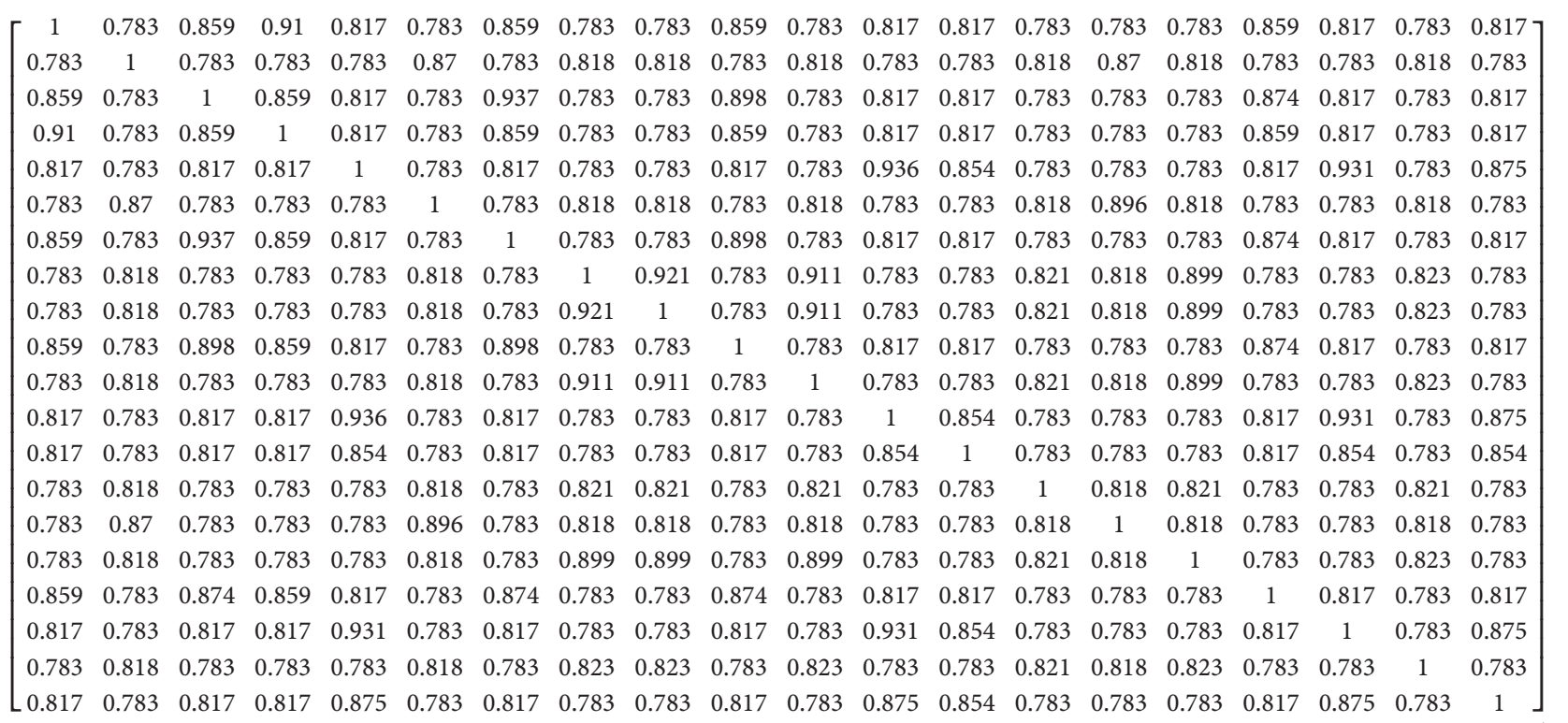


F-statistics method is used to determine the optimum threshold value $\lambda=0.91$, and the classification results for 20 detected samples according to condition attributes $C$ (four durability environmental regionalization indexes) and decision attributes $D$ (the durability damage level of the concrete components) are

$$
\begin{aligned}
\frac{U}{\operatorname{IND}(C)}= & \{\{1,4\},\{2\},\{3,7\},\{5,12,18\},\{6\},\{8,9,11\}, \\
& \{10\},\{13\},\{14\},\{15\},\{16\},\{17\},\{19\},\{20\}\} ; \\
\frac{U}{\operatorname{IND}(D)}= & \{\{2,9\},\{6,8,11,16\},\{1,3,7,10,15,17,19\},
\end{aligned}
$$$$
\{4,5,12,13,14,18,20\}\} \text {. }
$$

Similarly, after removing the condition attribute $c_{i}$, classify the condition attribute set $C$ by the fuzzy clustering methods, and all the best classifications were as follows:

$$
\begin{aligned}
& \frac{U}{\operatorname{IND}\left(C-\left\{c_{1}\right\}\right)}=\{\{1,4\},\{2,6,15\},\{3,7,10,17\}, \\
&\{5,12,18\},\{8,9,11,16\}, \\
&\{13\},\{14\},\{19\},\{20\}\} ; \\
& \frac{U}{\operatorname{IND}\left(C-\left\{c_{2}\right\}\right)}=\{\{1,3,4,7,10,13,15,17\},\{2\}, \\
&\{5,12,18\},\{6\}, \\
&\{8,9,11,16\},\{14\},\{19\},\{20\}\} ; \\
& \frac{U}{\operatorname{IND}\left(C-\left\{c_{3}\right\}\right)}=\{\{1\},\{2,16\},\{3,7,17\},\{4,14\},
\end{aligned}
$$

$\{5,12,18,20\}$,

$\{6,8,9,11\},\{10\},\{13\},\{15,19\}\}$;

$\frac{U}{\operatorname{IND}(C-\{c 4\})}=\{\{1,4\},\{2,6,15\}\{3,7\},\{5,12,18\}$,

$\{8,9,11,16,19\},\{10\}$,

$\{13\},\{14\},\{17\},\{20\}\}$.

Then solve the union lower of approximate set of each equivalence set of each durability damage level, respectively. Consider

$$
\begin{gathered}
\operatorname{POS}_{C}(D)=\{2,3,5,6,7,10,12,13,14,15,16,17,18,19,20\}, \\
\operatorname{POS}_{C-\left\{c_{1}\right\}}(D)=\{3,5,7,10,12,13,14,17,18,19,20\}, \\
\operatorname{POS}_{C-\left\{c_{2}\right\}}(D)=\{2,5,6,12,14,18,19,20\},
\end{gathered}
$$

$$
\begin{gathered}
\operatorname{POS}_{C-\left\{c_{3}\right\}}(D)=\{1,3,4,5,7,10,12,13,14,15,17,18,19,20\}, \\
\operatorname{POS}_{C-\left\{c_{4}\right\}}(D)=\{3,5,7,10,12,13,14,17,18,20\} .
\end{gathered}
$$

Then calculate the significance $\operatorname{SGF}\left(c_{i}, C, D\right)$ of each regionalization index $c_{i}$ through the dependence degree of durability damage level $D$ on the regionalization index set $C$ and the regionalization index set $C-c_{i}$. Consider

$$
\begin{aligned}
\operatorname{SGF}\left(c_{1}, C, D\right) & =\gamma_{C}(D)-\gamma_{C-\left\{c_{1}\right\}}(D) \\
& =\frac{\left|\mathrm{POS}_{C}(D)\right|}{|U|}-\frac{\left|\operatorname{POS}_{C-\left\{c_{1}\right\}}(D)\right|}{U} \\
& =\frac{15}{20}-\frac{11}{20}-\frac{4}{20}, \\
\operatorname{SGF}\left(c_{2}, C, D\right) & =\gamma_{C}(D)-\gamma_{C-\left\{c_{2}\right\}}(D) \\
& =\frac{\left|P_{C}(D)\right|}{|U|}-\frac{\left|\operatorname{POS}_{C-\left\{c_{2}\right\}}(D)\right|}{U} \\
& =\frac{15}{20}-\frac{8}{20}-\frac{7}{20}, \\
\operatorname{SGF}\left(c_{3}, C, D\right) & =\gamma_{C}(D)-\gamma_{C-\left\{c_{3}\right\}}(D) \\
& =\frac{\left|P_{C}(D)\right|}{|U|}-\frac{\left|\operatorname{POS}_{C-\left\{c_{3}\right\}}(D)\right|}{U} \\
& =\frac{15}{20}-\frac{10}{20}-\frac{5}{20} . \\
& =\frac{14}{20}-\frac{1}{20}, \\
\operatorname{SGF}\left(c_{4}, C, D\right) & =\gamma_{C}(D)-\gamma_{C-\left\{c_{4}\right\}}(D) \\
& =\frac{\left|\operatorname{POS}_{C-\left\{c_{4}\right\}}(D)\right|}{U}(D) \mid \\
& \\
&
\end{aligned}
$$

Finally, normalize the significance of each regionalization index $c_{i}$ and we can obtain the weight of the durability influencing factors:

$$
\left(\omega_{c_{1}}, \omega_{\mathcal{c}_{2}}, \omega_{\mathcal{c}_{3}}, \omega_{c_{4}}\right)=(0.2353,0.4118,0.0588,0.2941) .
$$

From Formula (21) we can see that, among the factors influencing concrete durability in Yantian district, the surface chloride concentration has the most influential effect, followed by the ambient relative humidity and concrete carbonation depth, while the ambient temperature had the least influence. After assessing the durability damage level of the 515 in-service concrete structures in Shenzhen city, the weight of each affecting factors for building's durability is obtained.

Considering the administrative division of Shenzhen city and roads regionalization of Longda Express highway, Guangshen Express highway, Jihe Express highway, Huishen 
TABLE 4: Result of durability environmental regionalization for concrete structures in Shenzhen city.

\begin{tabular}{|c|c|c|c|c|c|}
\hline \multirow[b]{2}{*}{ Regions } & \multicolumn{4}{|c|}{ Weight of durability environmental regionalization indexes } & \multirow[b]{2}{*}{ Geographical area } \\
\hline & $\begin{array}{l}\text { Surface chloride } \\
\text { concentration }\end{array}$ & $\begin{array}{l}\text { Concrete } \\
\text { carbonation } \\
\text { depth }\end{array}$ & $\begin{array}{c}\text { Ambient } \\
\text { temperature }\end{array}$ & $\begin{array}{c}\text { Ambient relative } \\
\text { humidity }\end{array}$ & \\
\hline I & $0.3154 \sim 0.4250$ & $0.1803 \sim 0.2560$ & $0.0154 \sim 0.1737$ & $0.0213 \sim 0.3125$ & $\begin{array}{l}\text { A narrow distribution along the coastline, } \\
\text { mainly in the south of } \\
\text { Guangzhou-Shenzhen highway }\end{array}$ \\
\hline II & $0.2758 \sim 0.3239$ & $0.2445 \sim 0.3460$ & $0.0758 \sim 0.1239$ & $0.0250 \sim 0.2375$ & $\begin{array}{l}\text { Central of Bao'an district, northern of } \\
\text { nanshan and Futian District, most parts } \\
\text { of the Luohu and Yantian district, } \\
\text { southern of Longgang district }\end{array}$ \\
\hline III & $0.1762 \sim 0.2618$ & $0.3219 \sim 0.4795$ & $0.0758 \sim 0.1998$ & $0.0219 \sim 0.1843$ & $\begin{array}{l}\text { Mainly in the north of Longda } \\
\text { expressway, huiyan Highway, and } \\
\text { Shenzhen-Shantou expressway }\end{array}$ \\
\hline
\end{tabular}

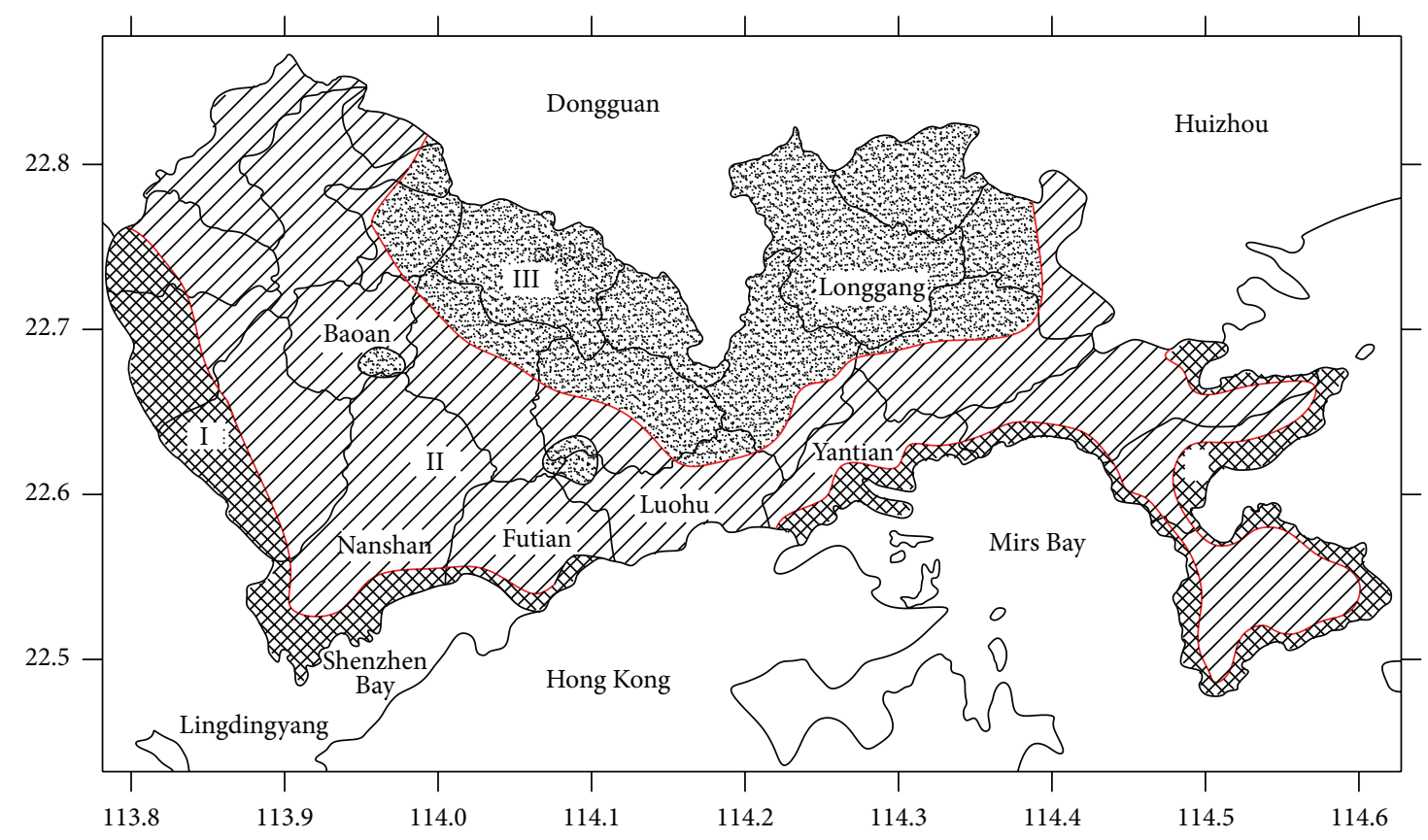

FIGURE 2: Regionalization map of durability environment for concrete structures in Shenzhen City.

Express highway, Huiyan Express highway, and so forth, the durability environmental regionalization can be made based on the weight of each influencing factor and deterioration characteristics of detected structures. The Shenzhen city is divided into three areas: Chloride Erosion area (I); Adjacent Sea Air area, which makes chloride erosion as main action and carbonization supplementary (II); and Common Air area, which makes carbonization as main action (III) (Table 4). According to the regionalization results, the durability regionalization map of concrete structures in Shenzhen city can be plotted as Figure 2 .

Table 2 and Figure 1 show that, among the factors affecting the durability of concrete structures from Chloride Erosion area (I) to Common Air area (III), the effect of chloride erosion is gradually weakened, while the effect of carbonization gradually become the dominant.
In the Chloride Erosion area (I), the relative humidity and atmospheric $\mathrm{Cl}^{-}$content are relatively high, steel reinforcement in concrete has severely deteriorated, and concrete cover exhibits a large number of cracks along the longitude rebar or even a large area of spalling. More attention should be paid on chloride erosion when doing structural durability design, and appropriate durability protective measures should be taken in this region.

Adjacent Sea Air area (II) covers most areas of the Shenzhen special economic zone. With the distance from costal line increasing, atmospheric $\mathrm{Cl}^{-}$content decreases rapidly. This is because the maritime air is forced to uplift due to the block of Lotus mountains, and the salt spray carried by the air is absorbed by most of the rocks and trees; besides, the air flow is blocked by the tall buildings in south of Shenzhen city, and most salt particles in the air were settled. The effect of 
chloride ion penetration and concrete carbonation should be considered during structural durability design in this region.

After salt particle settlement in Region I and Region II, the chloride concentration of the components surface decreased. Reinforced concrete structures in Common Air area (III) has mild rust occasionally, the concrete protective layer of reinforcement has a small amount longitude cracks due to insufficient thickness. concrete carbonation is the major factor that influences the durability of concrete in this area.

\section{Conclusion}

(1) The combination of dominant factor and comprehensive analysis method of the climatic zonation can be used in the macroenvironmental regionalization. Taking China for example, after comprehensive analysis of climate condition and erosion medium characteristics of China, property regionalization indexes can be selected, and China can be divided into six primary regions and thirteen secondary regions.

(2) A new way based on the fuzzy sets and rough sets to determine the weight distribution can be used in the microenvironmental regionalization. Based on discretization of the measured data, the significance of attributes among rough sets can be estimated instead of weight determination, and a relational data model about the durability effecting factors of concrete structures can be established. A knowledge system can be built through making attribute value into eigenvalue. After that, the method of durability environmental division for microenvironment can be established by analyzing the degree of influence various factors have on the durability of concrete structures.

(3) After researching on durability environmental regionalization for concrete structures in China and Shenzhen city, the proposed approach improved the accuracy and efficiency of comprehensive evaluation of the subjectivity of traditional environmental regionalization method, and the regionalization result, which will agree with the field situation of concrete durability degradation, is proved much more to be scientific and practical. Moreover, the recommended method provides a scientific basis to durability design and maintenance of reinforced concrete structures.

\section{Acknowledgments}

This work was supported by National Natural Science Foundation of China (Grant no. 51278403 and 51308445) and Scientific \& Technological Innovation Project of Shaanxi province (Grant no. 2010ZDKG-55). This work presented herein was conducted in the State Key Laboratory of Architecture Science and Technology in West China at Xian University of Architecture \& Technology. The authors gratefully acknowledge the support that has made this laboratory and its operation possible. In addition, the authors would also like to acknowledge the reviewers for their valuable comments of this paper.

\section{References}

[1] Vitruvius, Ten Books on Architecture, Cambridge University Press, Cambridge, UK, 1999.

[2] Standard of Climatic Regionalization For Architecture. GB, 50178-93, Chinese Plan Publication House, Beijing, China, 1993.

[3] W. Jin and Q. Lü, "Durability zonation standard of concrete structure design," Journal of Southeast University, vol. 23, no. 1, pp. 98-104, 2007.

[4] V. G. Papadakis, C. G. Vayenas, and M. N. Fardis, "Fundamental modeling and experimental investigation of concrete carbonation," ACI Materials Journal, vol. 88, no. 4, pp. 363-373, 1991.

[5] S. Morinaga, "Prediction of service lives of reinforced concrete buildings based on the corrosion rate of reinforcing steel," in Proceedings of the 5th international conference on Durability of Building Materials and Components, pp. 5-13, 1990.

[6] J. N. Enevoldsen, C. M. Hansson, and B. B. Hope, "The influence of internal relative humidity on the rate of corrosion of steel embedded in concrete and mortar," Cement and Concrete Research, vol. 24, no. 7, pp. 1373-1382, 1994.

[7] V. Živica, L. Krajči, L. BágeL', and M. Vargová, “Significance of the ambient temperature and the steel material in the process of concrete reinforcement corrosion," Construction and Building Materials, vol. 11, no. 2, pp. 99-103, 1997.

[8] H. S. Shang, T. H. Yi, and Y. P. Song, "Behavior of plain concrete of a high water-cement ratio after freeze-thaw cycles," Materials, vol. 5, no. 9, pp. 1698-1707, 2012.

[9] H. Cai and X. Liu, "Freeze-thaw durability of concrete: ice formation process in pores," Cement and Concrete Research, vol. 28, no. 9, pp. 1281-1287, 1998.

[10] D. Niu, Durability and Life Prediction of Concrete Structures, Science Press, Beijing, China,, 2003.

[11] J. A. Gonzalez and C. Andrade, "Effect of carbonation, chlorides and relative ambient humidity on the corrosion of galvanized rebars embedded in concrete," British Corrosion Journal, vol. 17, no. 1, pp. 21-28, 1982.

[12] K. A. T. Vu and M. G. Stewart, "Structural reliability of concrete bridges including improved chloride-induced corrosion models," Structural Safety, vol. 22, no. 4, pp. 313-333, 2000.

[13] J. P. Lacaux, J. Servant, and J. G. R. Baudet, "Acid rain in the tropical forests of the Ivory Coast," Atmospheric Environment, vol. 21, no. 12, pp. 2643-2647, 1987.

[14] F. Höppner, F. Klawonn, K. Rudolf, and R. Thomas, Fuzzy Cluster Analysis: Methods for Classification, Data Analysis and Image Recognition, John Wiley and Sons, 1999.

[15] H.-J. Zimmermann, Fuzzy Set Theory and Its Applications, Springer, 2001.

[16] J. Xie, Fuzzy Mathematics Method and Applications, Press of Huazhong University of Science and Technology, Wuhan, China, 2000.

[17] Z. Pawlak, Rough Sets-Theoretical Aspects of Reasoning About Data, Kluwer Academic, Boston, Mass, USA, 1991.

[18] Z. Pawlak, J. Grzymala-Busse, R. Slowinski, and W. Ziarko, "Rough sets," Communications of the ACM, vol. 38, no. 11, pp. 88-95, 1995. 
[19] Z. Pawlak, "Rough set theory and its applications to data analysis," Cybernetics and Systems, vol. 29, no. 7, pp. 661-688, 1998.

[20] Z. Pawlak, "Rough sets and intelligent data analysis," Information Sciences, vol. 147, no. 1-4, pp. 1-12, 2002.

[21] I. Duntsch and G. Gediga, "Weighted $\lambda$ precision models in rough set data analysis," in Proceedings of the Federated Conference on the Computer Science and Information Systems (FedCSIS '12), pp. 287-294, 2012.

[22] T. Yi, H. Li, and X. Zhao, "Noise smoothing for structural vibration test signals using an improved wavelet thresholding technique," Sensors, vol. 12, no. 8, pp. 11205-11220, 2012.

[23] H. Shang, T. Yi, and L. Yang, "Experimental study on the compressive strength of big mobility concrete with nondestructive testing method," Advances in Materials Science and Engineering, vol. 2012, Article ID 345214, 6 pages, 2012.

[24] China Engineering Construction Standardization Association. Standard For Durability Assessment of Concrete Structures (CECS 220:2007), China building industry Press, Beijing, China, 2007. 


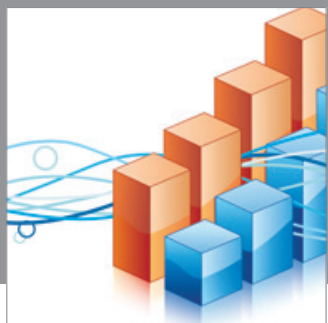

Advances in

Operations Research

mansans

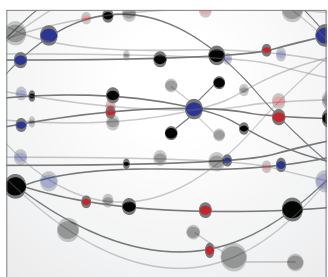

The Scientific World Journal
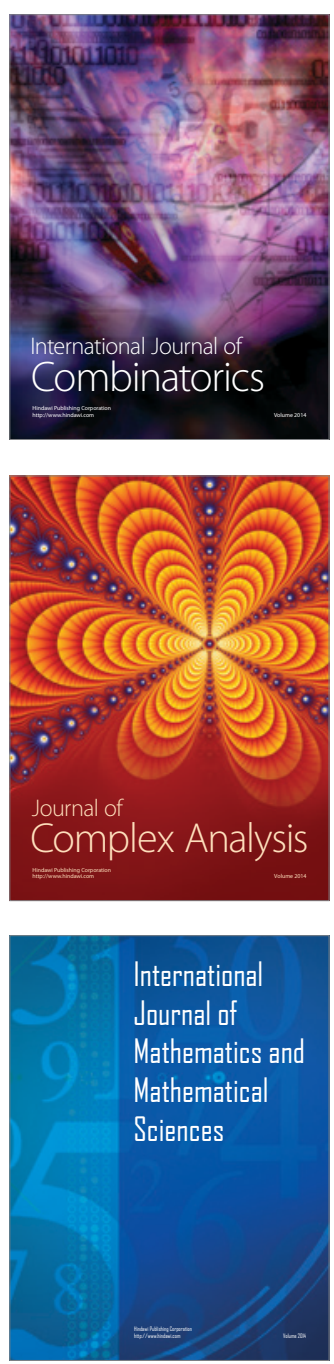
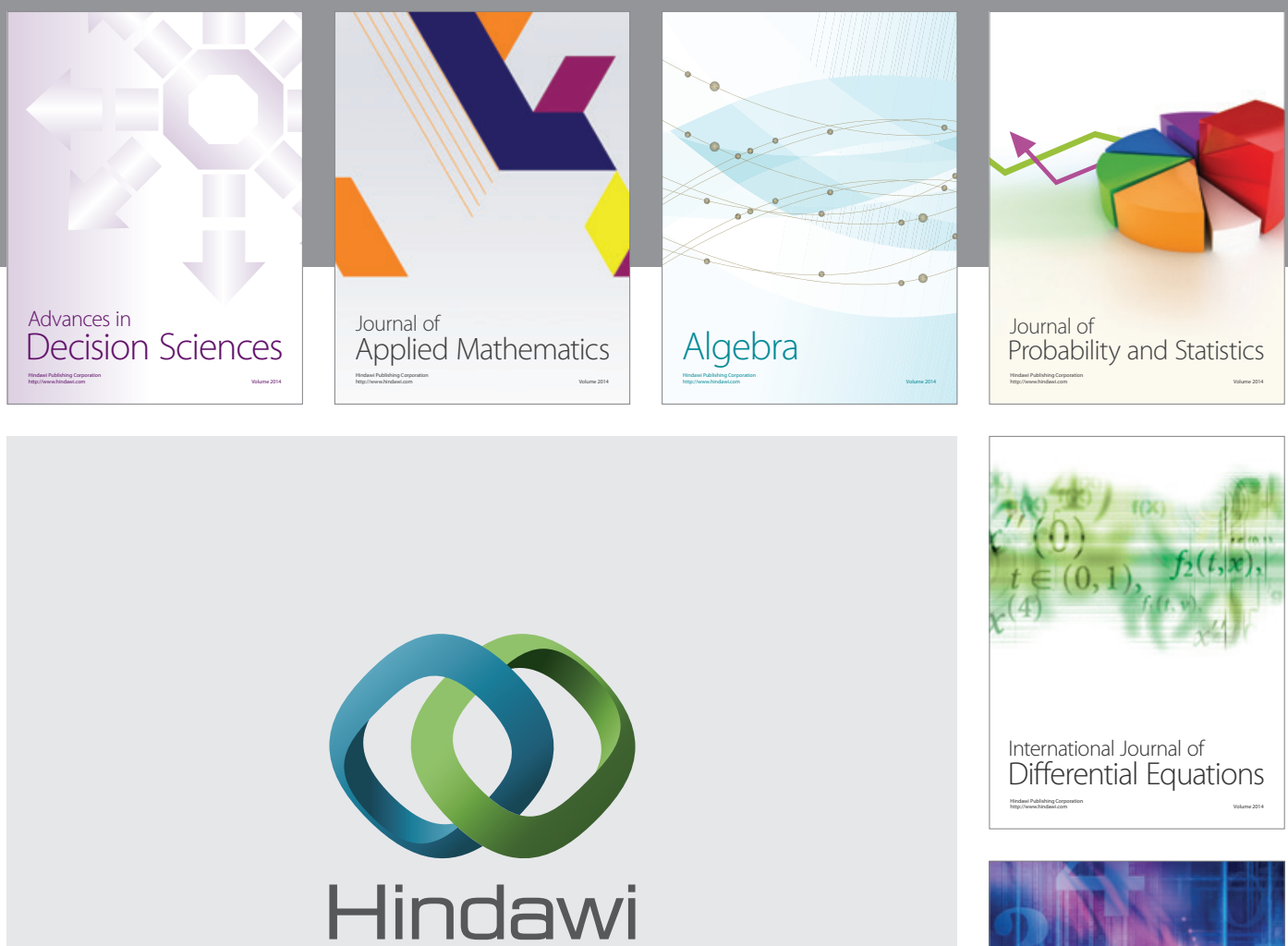

Submit your manuscripts at http://www.hindawi.com
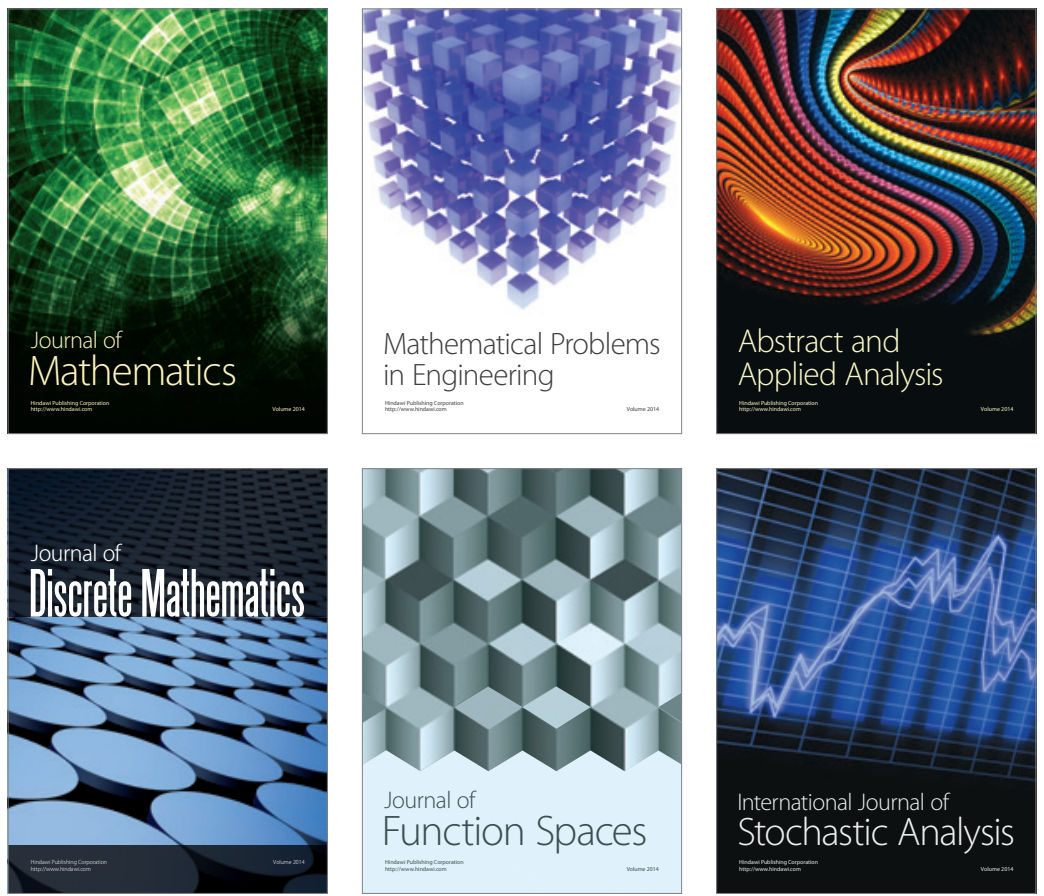

Journal of

Function Spaces

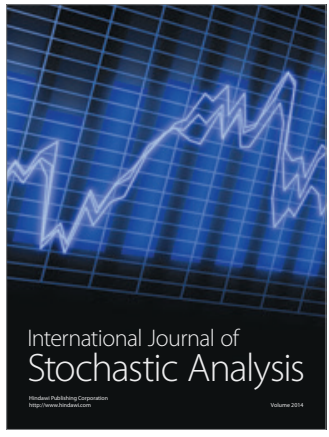

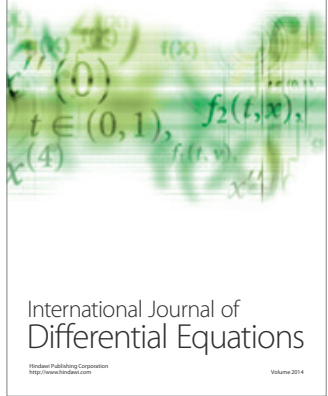
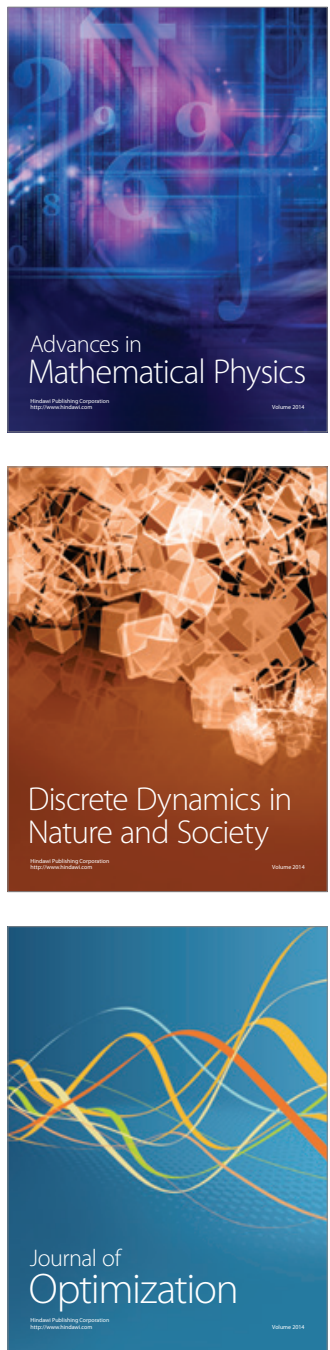